\title{
Flow Characterisation of Transpiring Porous Media for Hypersonic Vehicles
}

\author{
Hassan Saad Ifti*, Tobias Hermann ${ }^{\dagger}$, and Matthew McGilvray ${ }^{\ddagger}$ \\ Oxford Thermofluids Institute, University of Oxford, Oxford, OX2 OES, United Kingdom
}

\begin{abstract}
This paper experimentally examines the internal and external flow characteristics of porous zirconium diboride $\left(\mathrm{ZrB}_{2}\right)$, an Ultra-High-Temperature-Ceramic (UHTC) and a potential candidate for transpiration cooling of hypersonic vehicles. This is performed for both partially sintered material and fully densified material with cast features. The Darcy and Forchheimer permeability coefficients of these samples are determined using an ISO standard test rig. The outflow of the transpiring porous samples is investigated where no hypersonic cross-flow is involved using hot-wire anemometry and focused Schlieren visualisation. The velocity maps obtained from the hot-wire data show significant non-uniformities across the UHTC's outflow region, both at low and high differential pressures. The focused Schlieren using carbon dioxide as the injected gas reveals unsteady structures at high differential pressures as the outflowing gas interacts with the surrounding air.
\end{abstract}

\section{Nomenclature}

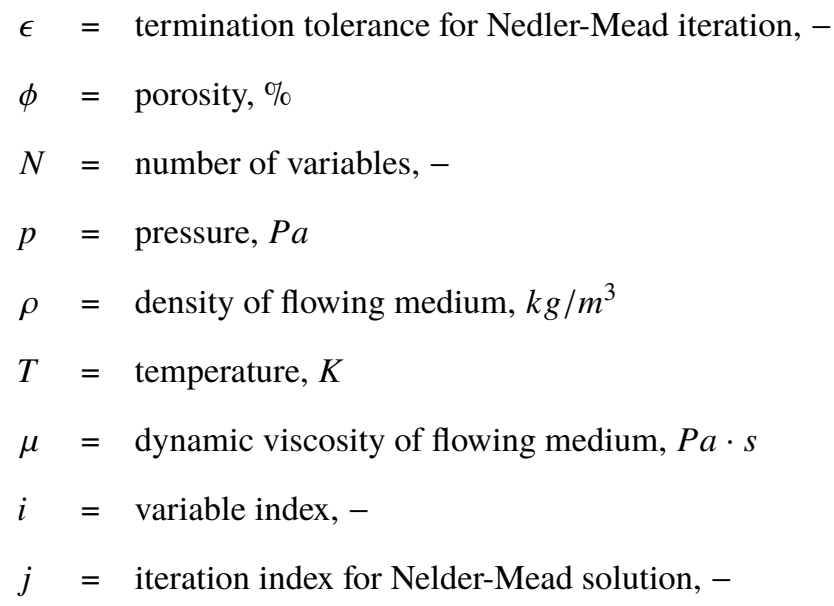

\footnotetext{
*D.Phil. Candidate, Hypersonics Group, OTI, Department of Engineering Science, University of Oxford, AIAA Member, Email: saad.ifti@eng.ox.ac.uk

${ }^{\dagger}$ Post-doctoral Research Assistant, Hypersonics Group, OTI, Department of Engineering Science, University of Oxford, AIAA Member

$¥$ Associate Professor, Hypersonics Group, OTI, Department of Engineering Science, University of Oxford.
} 


\section{Introduction}

The flow around a hypersonic vehicle is characterised by certain physical flow phenomena, e.g. viscous interaction, high-temperature effects, etc., and the resulting high heat load become detrimental for the vehicle at very high Mach numbers, especially during the re-entry into Earth's atmosphere or planetary entry, e.g. to Mars. At re-entry speeds $(>6.5 \mathrm{~km} / \mathrm{s})$, it becomes highly challenging for an entry body to return back to Earth due to the high heat load on the vehicle's surface [1]. Therefore, various Thermal Protection Systems (TPS) are in use today which protect the payload from the shocked hot gas. In addition to the TPS needs of hypersonic spacecraft in use today, envisaged re-usable hypersonic passenger vehicles, such as the Skylon [2], will require protection from high heat loads [3]. Therefore, an interest in further research on re-usable and high performing thermal protection systems exists, where transpiration cooling is considered as one of the most promising candidates [4]. Transpiration cooling has the potential to minimise or remove the use of ablative material and increase reusability of spacecraft. However, this comes at a cost of added complexity and could add weight to the vehicle.

The cooling process by transpiration generally takes place by three different but simultaneous effects. A schematic of the process is shown in Fig. 1. The pressurised coolant gas finds its way out of the reservoir through the porous material and thereby absorbs the heat from it by natural convection. This keeps cooling the material as long as there is a temperature gradient between the material and the coolant gas, which accounts for the first effect. The second effect comes into play when the injected coolant gas leaves the porous material and convects downstream (see Fig. $1 \mathrm{p}$ ). This creates a thin blanket or layer of coolant gas which acts as an insulation between the wall and the incoming hot gas flow and thus prevents the wall from overheating. In addition, if the material can be raised to a higher temperature, the rate of heat radiated back into space can be increased. In contrast to ablative heat shields, transpiration cooled systems are not subject to the detrimental effects of spallation, a process that leads to an increase of heat flux, especially downstream of the stagnation point. This however requires the avoidance of oxidation, which can be the third effect of transpiration cooling if an inert gas is used as the coolant.

The amount of coolant can be actively varied by modifying the injection rates, although this is limited due to the potential lift-off of the jets which could lead to early transition [5]. The incoming boundary-layer thickens due to the blanket (layer) of coolant gas as shown in Fig. 1 p. The coolant gas eventually starts mixing with the boundary-layer; consequently, the insulating blanket diminishes at some downstream location depending on the strength of mixing. Hence, from an application's point of view, this length of the effective insulating blanket (i.e. effectiveness), the mixing, and the injection are of immense importance. However, to fully comprehend these complex phenomena, it is sensible to first understand the behaviour of the outflow through porous media without the complications introduced by the hypersonic cross-flow. 
(a)

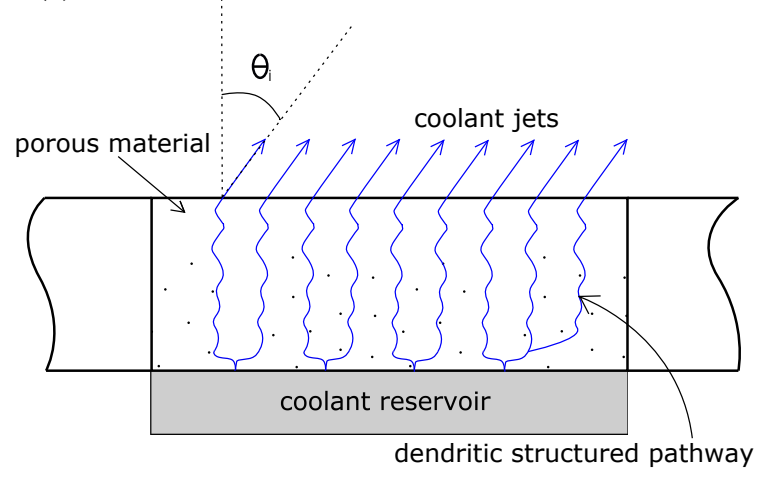

(b)

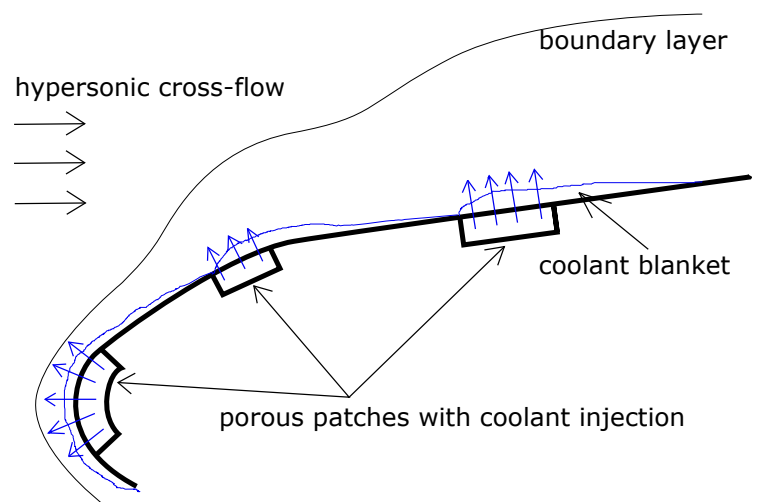

Fig. 1 Schematic: (a) coolant injection at an arbitrary inclination of $\theta_{i}$ and (b) arbitrary leading edge of a hypersonic vehicle with porous, transpiration cooling patches. Note: the blue layers indicate the coolant blankets (not to scale).

Various materials from metals to ceramic matrix composites (CMC) have been investigated as potential porous media for hypersonic application. Carbon-carbon (C/C) type CMC has been used quite extensively for transpiration cooling experiments by DLR [6-8], ITLR [9, 10], and IRS [11]. The reason for this choice lies in its high operational temperature of approx. $1800 \mathrm{~K}$ [9], producibility, and, foremost, high specific strength and modulus [12]. Gascoin et al. [13-15] performed permeability tests on stainless steel, bronze, and CMCs, and reported their permeability coefficients. Further, Dittert et al. [7] showed that the outflow of porous CMC exhibits significant local non-uniformities which could potentially lead to film separation or early transition. It is important to analyse the outflow characteristics of a particular sample in order to interpret the respective influence of coolant injection into a cross-flow.

In this paper, porous samples made of zirconium diboride $\left(\operatorname{Zr} B_{2}\right)$, a UHTC, are experimentally studied for their permeability and outflow characteristics. The Darcy and Forchheimer coefficients are determined for samples of different porous structures and porosities using a dedicated ISO standard [16] test rig. The uniformity and jet behaviour of the outflow are measured and observed using hot-wire anemometry and visualised using focused Schlieren imaging. To the authors' knowledge, this is the first time that UHTCs are examined for the purpose of transpiration cooling.

\section{UHTC Samples}

The porous UHTC samples used for this paper are made of zirconium diboride $\left(\operatorname{Zr} B_{2}\right)$, which has a density of $\rho_{\phi=100 \%}=6080 \mathrm{~kg} / \mathrm{m}^{3}$ in a $100 \%$ densified state. The melting point and thermal conductivity of $\mathrm{Zr} B_{2}$ are $3505 \mathrm{~K}$ [17] and $56 \mathrm{~W} / \mathrm{mK}$ [18], respectively. The different porosities and porous structures in these samples are achieved by partial sintering (see Fig. 2) and creating cast features using starch fugitives in totally densified material. An overview of the tested samples are given in Table 1 . In total, one cast featured sample and seven partially sintered samples were tested. A layer of residue could be observed on the surfaces of some of the partially sintered samples, and therefore it was decided to abrade the surfaces with sandpaper. Subsequently, samples UHTC-2, UHTC-3, and UHTC-4 were tested 
for their permeability characteristics before and after sanding the surface with sandpaper. The next batch of samples, i.e. UHTC-5 to UHTC-8, was treated in an ultrasonic bath to get rid of the residue, and to verify the effectiveness of the ultrasonic bath, permeability tests were performed on UHTC-6 before and after sanding.

(a)

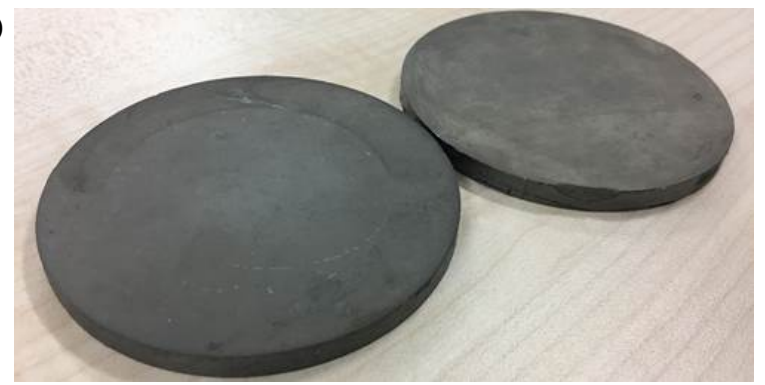

(b)

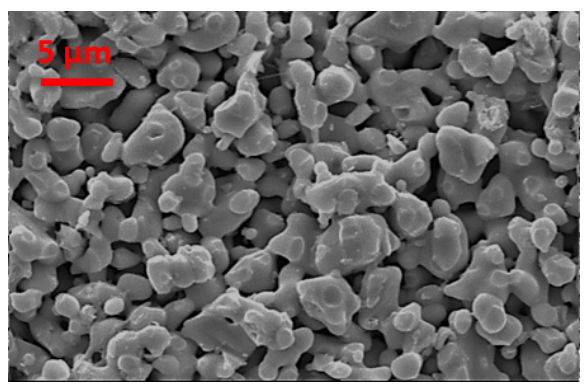

(c)

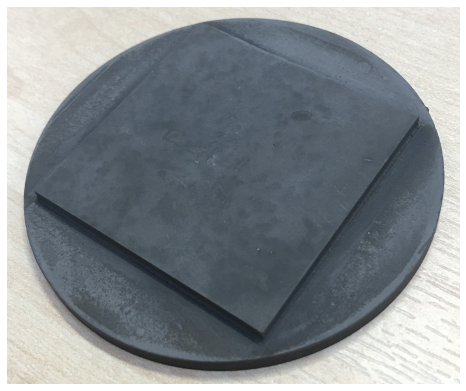

Fig. $2 \mathrm{ZrB} B_{2}$ porous sample: (a) $70 \mathrm{~mm}$ diameter samples with $5 \mathrm{~mm}$ thickness, (b) a sample's microstructure (courtesy: Imperial College London), and (c) a sample machined with EDM.

\begin{tabular}{lrrrll}
\hline sample ID & porosity, $\phi[\%]$ & $D[\mathrm{~mm}]$ & $L[\mathrm{~mm}]$ & type & treatments \\
\hline UHTC-1 & 24.7 & 33 & 5 & cast featured (starch) & none \\
UHTC-2 & 42 & 70 & 5 & partially sintered & abrasion \\
UHTC-3 & 41 & 70 & 5 & partially sintered & abrasion \\
UHTC-4 & 41 & 70 & 5 & partially sintered & abrasion \\
UHTC-5 & 41 & 80 & 5 & partially sintered & ultrasonic bath \\
UHTC-6 & 41.1 & 80 & 5 & partially sintered & ultrasonic bath, abrasion \\
UHTC-7 & 41.6 & 80 & 5 & partially sintered & ultrasonic bath \\
UHTC-8 & 40.9 & 80 & 5 & partially sintered & ultrasonic bath \\
\hline
\end{tabular}

Table 1 UHTC sample overview.

After completing the permeability tests, all samples were machined with Electrical Discharge Machining (EDM) into a disc form of $\varnothing 60 \mathrm{~mm} \times 3 \mathrm{~mm}$ with an extrude of $39.5 \mathrm{~mm} \times 39.5 \mathrm{~mm} \times 2 \mathrm{~mm}$ (see Fig. 22) for the outflow experiments. 


\section{Darcy-Forchheimer Permeability Test}

The pressure drop across a porous medium is governed by the Darcy-Forchheimer equation, expressed in differential form as

$$
-\frac{d p}{d x}=\underbrace{\frac{\mu}{K_{D}} v}_{\text {viscous term }}+\underbrace{\frac{\rho}{K_{F}} v^{2}}_{\text {kinetic term }} .
$$

Here, $K_{D}$ and $K_{F}$ are material intrinsic permeability coefficients respectively known as the Darcy coefficient and the Forchheimer coefficient; $v$ is the superficial velocity of the flowing medium (also known as the bulk velocity). The left-hand-side of Eq.(1) stands for the pressure gradient across the porous medium, whereas the two terms on the right-hand-side denote the viscous and kinetic losses, respectively. At very low velocities, the kinetic term is negligible and the flow is in the Darcy regime. In this case, the kinetic term of Eq.(1) is left out and the equation becomes the Darcy equation. However, at higher velocities, the kinetic term dominates and the flow enters the Forchheimer regime, requiring the full Darcy-Forchheimer equation. Note, these regimes are not to be confused with the laminar-turbulent regimes. A flow in the Forchheimer regime does not necessarily mean the flow is turbulent.

Integrating Eq.(1) over the thickness, $L$, of the porous medium with a constant temperature $T_{\text {in }}$ in the whole domain yields the equation

$$
\frac{p_{\text {in }}^{2}-p_{\text {out }}^{2}}{2 p_{\text {in }} L}=\frac{\mu\left(T_{\text {in }}\right)}{K_{D}} v_{\text {in }}+\frac{\rho_{\text {in }}\left(p_{\text {in }}, T_{\text {in }}\right)}{K_{F}} v_{\text {in }}^{2}
$$

where the subscripts 'in' and 'out' respectively denote input and output quantities. From an application's perspective, Eq.(2) provides a direct correlation between the coolant reservoir pressure, $p_{i n}$, and the outer pressure, $p_{\text {out }}$. The

normalised differential pressure, $\frac{p_{\text {in }}^{2}-p_{\text {out }}^{2}}{2 p_{\text {in }} L}$, is henceforth expressed as $\frac{\Delta p}{L}$. Since the dynamic viscosity—calculated from Sutherland's law [19]—and the density—obtained from the ideal gas law—of the fluid are functions of temperature, a modified version of Eq. 22] proposed by Langener et al. [9] can be used in the case of a thermal gradient in the material. However, Eq. (2) is sufficient for the purpose of this paper as the temperature non-uniformity is negligible for the conducted experiments.

\section{A. ISO 4022 Permeability Test Rig}

In order to determine the permeability coefficients, a test rig has been designed and built in accordance with the ISO 4022 standard [16]. The porous sample is clamped between the upstream and downstream parts as shown in Fig. 3. A K-type thermocouple (T/C) and a pressure transducer (Gems 3100 Series) are fitted to either part; these record the values of $T_{1}=T_{\text {in }}, T_{2}=T_{\text {out }}, p_{1}=p_{\text {in }}$, and $p_{2}=p_{\text {out }}$. During a test, the input pressure is increased in steps-potentially up to 400 psi (27.579 bar) — using a fine pressure regulator (Fairchild 10292 H). Adhering to the ISO 4022 standard, the mass flow rate is measured at a downstream location (Alicat M Series mass flow meter). The through-flow area for this rig is $A=1.911 \times 10^{-4} \mathrm{~m}^{2}$ (through-flow diameter of $15.6 \mathrm{~mm}$ ). 


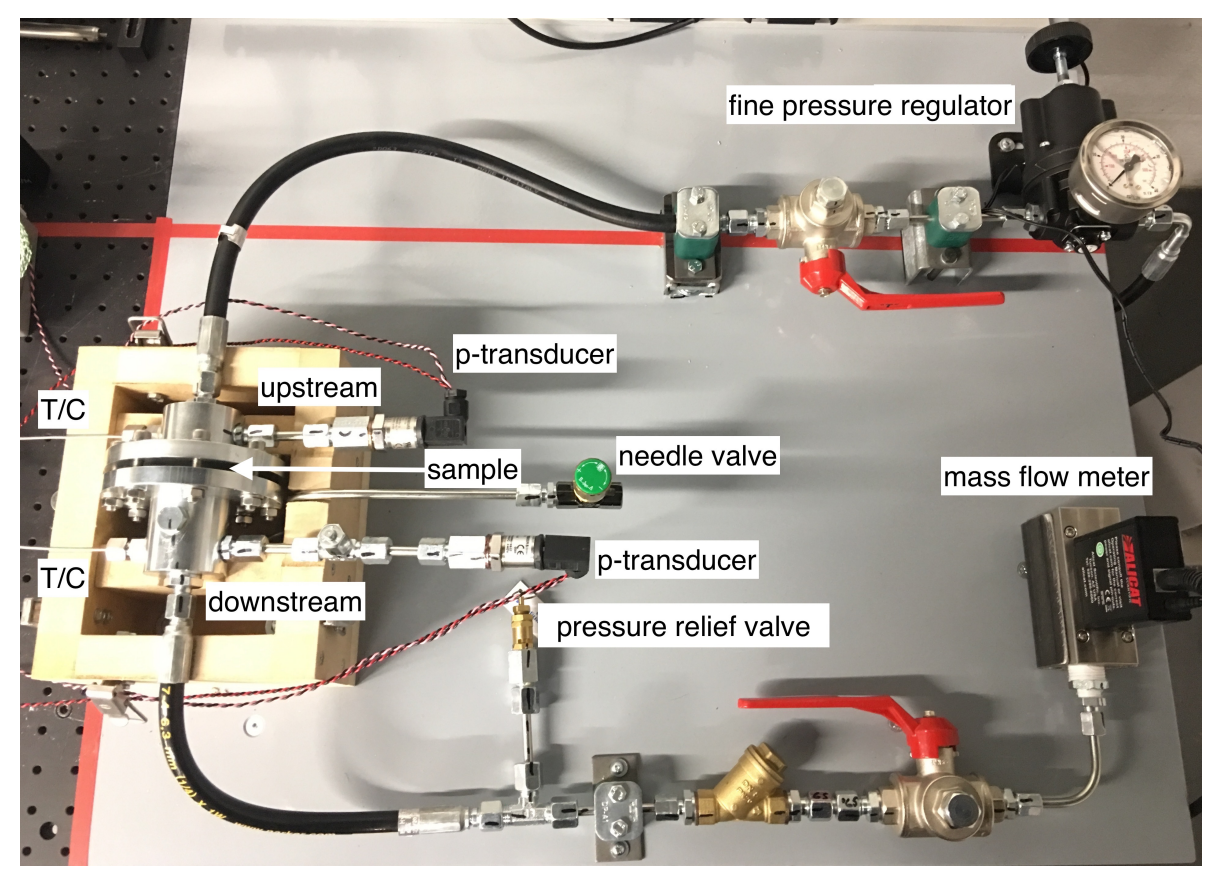

Fig. 3 The Darcy-Forchheimer ISO 4022 Permeability Test Rig.

Since $\rho_{i n}=\rho_{i n}\left(p_{i n}, T_{i n}\right)$, the input density changes for every data point. Hence, Eq. (2) spans a multi-dimensional space, and a curve-fit by linear regression in a two-dimensional space is no longer sufficient to obtain the permeability coefficients, $K_{D}$ and $K_{F}$. Therefore, a gradient-free optimisation method proposed by Nelder \& Mead [20] is employed. The minimisation criterion for this simplex search solution is given by

$$
f(\vec{K})=\frac{\left\|\left.\frac{\Delta p}{L}\right|_{\text {theoretical }}-\left.\frac{\Delta p}{L}\right|_{\text {experimental }}\right\|}{\left\|\left.\frac{\Delta p}{L}\right|_{\text {experimental }}\right\|}
$$

where $\vec{K}=\left[K_{D} K_{F}\right]^{T}$. Here, $\left.\frac{\Delta p}{L}\right|_{\text {experimental }}$ is obtained from the experimental data points, $\left.\frac{\Delta p}{L}\right|_{\text {theoretical }}$ is given by the right-hand-side of Eq.(2), and the symbol \|.\| denotes the euclidean norm. For a two-dimensional space, the Nelder-Mead algorithm employs three points and—for each iteration—picks the best point which satisfies $f=f_{\min }$. Per iteration, the three points are updated by reflection, outside/inside contraction, and shrinking until the conditions $\left|f^{(j+1)}-f^{(j)}\right| \leq \epsilon$ and $\left|\vec{K}^{(j+1)}-\vec{K}^{(j)}\right| \leq \epsilon$ both are fulfilled. A termination tolerance of $\epsilon=1 \times 10^{-10}$ is selected here.

\section{B. Uncertainty Analysis}

The uncertainties in the variables $\frac{\Delta p}{L}, \mu v_{i n}$, and $\rho_{i n} v_{i n}^{2}$ were calculated using Moffat's error propagation method [21] defined as

$$
\delta X=\sqrt{\sum_{i=1}^{N}\left(\frac{\partial X}{\partial Y_{i}} \delta Y_{i}\right)^{2}},
$$


where each variable is given as $X=X\left(Y_{1}, Y_{2}, \ldots, Y_{N}\right)$. Here, $X$ is the variable which is calculated from measurements, $Y_{i}$, using data from the experiment. The uncertainties in $Y_{i}$, denoted by $\delta Y_{i}$, are determined from the uncertainty given by the manufacturer of the employed equipment. In order to find the uncertainties in the permeability coefficients, a Monte Carlo simulation was performed for $1 \times 10^{6}$ events. For this purpose, $1 \times 10^{6}$ random events were created for the aforementioned variables around each experimental data point which followed a Gaussian distribution. The Gaussian

distribution was defined by an expected value of $E=X$ and a standard deviation of $\sigma=\frac{\delta X}{2}$. Hence, the uncertainty $\delta X$ was given by a confidence interval of $95 \%$ for each variable, and thus the process 'simulated' $1 \times 10^{6}$ events of the same experiment within the given bounds of uncertainty. Subsequently, the Nelder-Mead simplex search optimisation process was carried out for each event, hence $1 \times 10^{6}$ times, which yielded Gaussian distributions for $K_{D}$ and $K_{F}$. The uncertainties for the permeability coefficients were determined as $\delta K_{D}= \pm 2 \sigma$ and $\delta K_{F}= \pm 2 \sigma$-and therefore within a confidence interval of $95 \%$ - from their respective distributions.

\section{Validation}

In order to validate the results obtained from the permeability test rig, a porous disc of sintered bronze (SIKA-B 8: $89 \% \mathrm{Cu}+11 \% \mathrm{Sn}$ ) (see Fig. 4 a) provided by GKN Sinter Metals Filters GmbH was tested. The obtained permeability coefficients along with the permeability coefficients stated on the manufacturer's data sheet [22] for SIKA-B 8 are given in Table 2. The corresponding test results are illustrated in Fig. 4d.

\begin{tabular}{lrr}
\hline source & $K_{D}\left[10^{-12} \mathrm{~m}^{2}\right]$ & $K_{F}\left[10^{-6} \mathrm{~m}\right]$ \\
\hline ISO 4022 experiment & 2.162 & 1.023 \\
SIKA-B data sheet [22] & 2 & 5.2 \\
Ergun approximation & 1.768 & 1.537 \\
\hline
\end{tabular}

Table 2 Permeability coefficients of SIKA-B 8.

Whilst the Darcy coefficient obtained from the experiment is in close agreement with that from the data sheet, the Forchheimer coefficient is lower by a factor of approx. 5. In Fig. $4 \mathrm{~d}$, it can be seen that the normalised differential pressure (blue dot-dashed line) obtained from Eq. 2] using the coefficients from the data sheet under-predicts the pressure loss across the medium in comparison to the experimental data as the superficial input velocity increases. This is due to the fact that the manufacturer performed the permeability tests at very low differential pressures [22] where the flow was in the Darcy regime only, and thus the test did not capture a representative Forchheimer coefficient. Hence, despite matching the Darcy coefficient with a discrepancy of only $7.5 \%$, a different approach to validating the rig was required to account for the flow in the Forchheimer regime. 
(a)

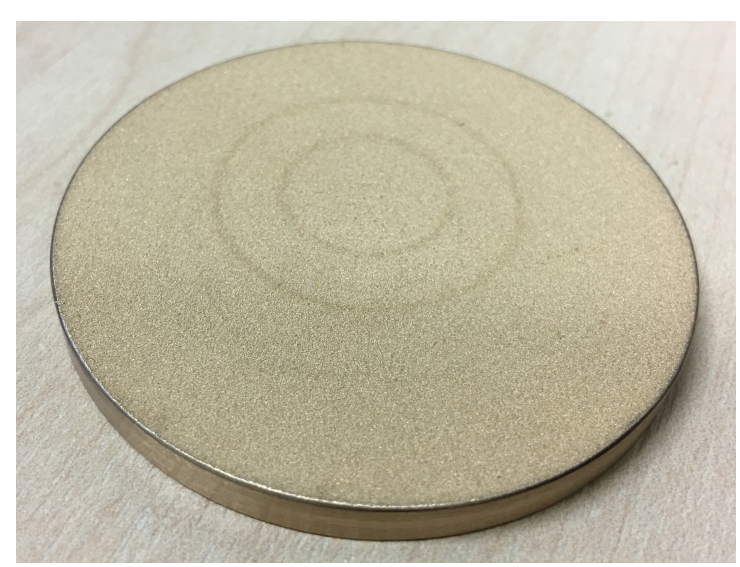

(c)

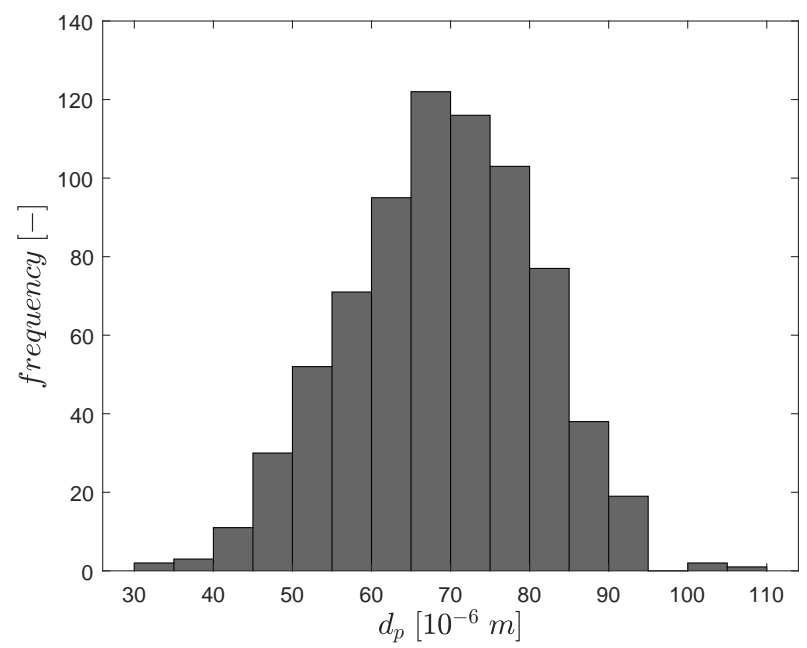

(b)

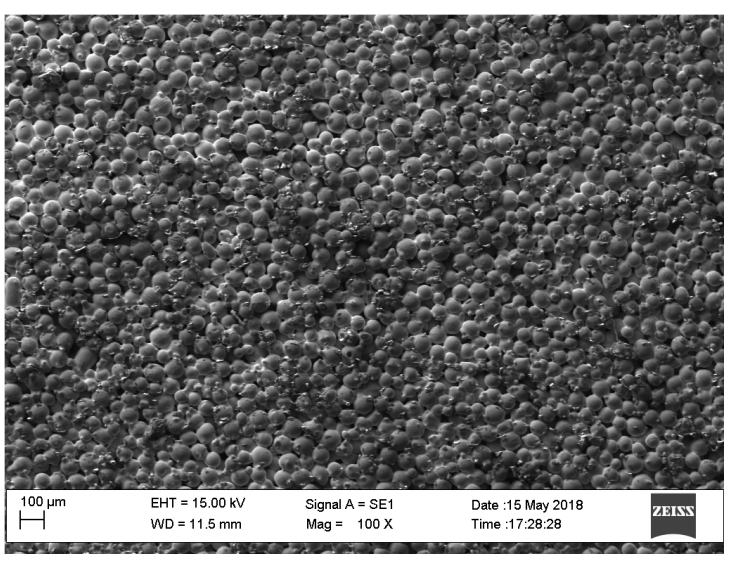

(d)

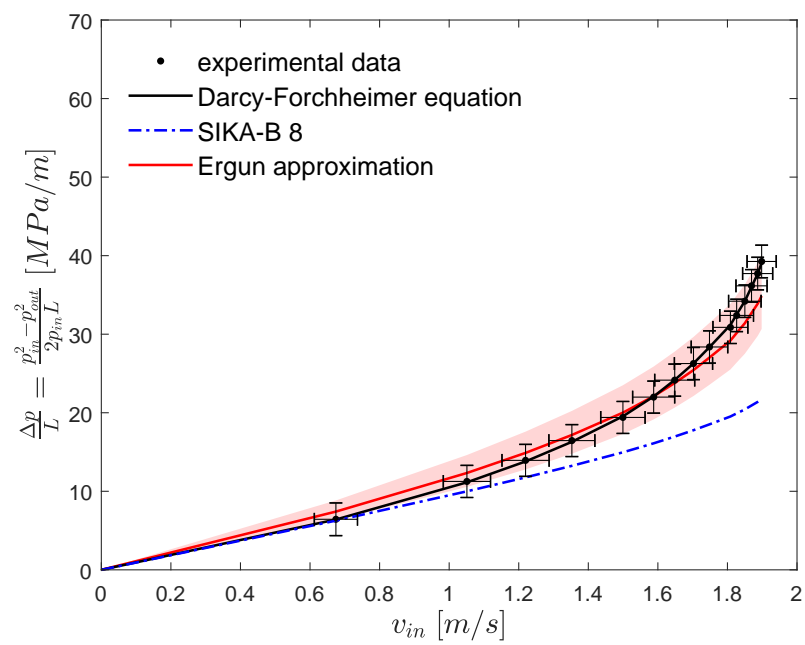

Fig. 4 Validation: (a) SIKA-B $8(\varnothing 60 \mathrm{~mm} \times 5 \mathrm{~mm})$, (b) SEM image of SIKA-B 8 at 100 $\times$ magnification, (c) histogram of the diameter of 742 particles of SIKA-B 8, and (d) normalised differential pressure versus superficial input velocity of SIKA-B 8 (the light-red band represents the uncertainty in Ergun approximation).

A comprehensive study on flow through packed beds was conducted by Ergun [23], where the Darcy and Forchheimer coefficients were respectively proposed as

$$
K_{D, \text { Ergun }}=\frac{\phi^{3} d_{p}^{2}}{150(1-\phi)^{2}}
$$

and

$$
K_{F, \text { Ergun }}=\frac{\phi^{3} d_{p}}{1.75(1-\phi)}
$$


Here, $d_{p}$ is the diameter of the particles in the packed bed. Since the SIKA-B 8 sample is made of regular spherical particles [22], these correlations are appropriate for modelling the flow through it. However, the diameter of the particles or the distribution thereof was not provided in the data sheet catalogue, nor was it possible to obtain it from the manufacturer. Therefore, SEM images (see Fig. 4p; courtesy: Dr Elsiddig Elmukashfi, Department of Engineering Science, University of Oxford) of the sample's surface were taken to measure the particle diameter, where the scale on the SEM images was taken as the reference. The measured diameter, $d_{p}$, of $n_{p}=742$ particles yielded a distribution shown in Fig. 4t with a mean of $\overline{d_{p}}=68.935 \times 10^{-6} \mathrm{~m}$ and a standard deviation of $\sigma_{d_{p}}=11.764 \times 10^{-6} \mathrm{~m}$ (fitted to a Gaussian distribution). Furthermore, a density based calculation determined a porosity of $\phi=30.1 \%$.

Now, substituting Eq.(5) and Eq(6) in Eq.27 yields

$$
\frac{\Delta p}{L}=\frac{150(1-\phi)^{2} \mu\left(T_{i n}\right)}{\phi^{3} d_{p}^{2}} v_{i n}+\frac{1.75(1-\phi) \rho_{i n}\left(p_{i n}, T_{i n}\right)}{\phi^{3} d_{p}} v_{i n}^{2}
$$

Since the diameter is a distribution, the normalised differential pressure was evaluated at the mean to approximate the flow through the sample (henceforth annotated as 'Ergun approximation'). The corresponding permeability coefficients are given in Table 2. In Fig. 44, it can be seen that the Ergun approximation (red, solid line) lies well within the uncertainty bounds of the experimental data. Further, the light-red band here represents the uncertainty in the Ergun approximation, which was obtained from the uncertainties in the mean diameter, $\bar{d}_{p}$. The total uncertainty in the mean is given as

$$
\delta \bar{d}_{p}=\sqrt{P_{\bar{d}_{p}}^{2}+B_{\bar{d}_{p}}^{2}}
$$

where $P_{\overline{d_{p}}}$ and $B_{\overline{d_{p}}}$ are the precision and bias uncertainties, respectively [24]. The precision uncertainty for a mean value within a confidence interval of $95 \%$ is calculated from the equation

$$
P_{\overline{d_{p}}}=\frac{2 \sigma_{d_{p}}}{\sqrt{n_{p}}}
$$

The systematic bias uncertainty, $B_{\bar{d}_{p}}$, in this case is the uncertainty in the diameter measurement from the SEM images. This was estimated to be equivalent to two pixels and equal for all measurements. The obtained total uncertainty in the mean diameter, $\delta \bar{d}_{p}$, was subsequently used to determine the uncertainty in the Ergun approximation from Eq. (7) employing Moffat's error propagation method described earlier.

Overall, the experimental data and the Ergun approximation, along with their respective uncertainties, are in good agreement, and the validation is thereby concluded. 


\section{Results}

The permeability coefficients for all eight UHTC samples yielded from the Nelder-Mead simplex search solution are given in Table 3 along with their respective uncertainties. The intermediate results are showcased in Fig. 5 for UHTC-3 (post-sand). The normalised differential pressure is plotted against the superficial input velocity including the uncertainties of the experimental data in form of error bars in Fig. 5a; the solid line here, which represents the DarcyForchheimer equation, is obtained by using the $K_{D}$ and $K_{F}$ values in Eq.(2). The corresponding mass flow rate through an area of $A=1.911 \times 10^{-4} \mathrm{~m}^{2}$ on the porous sample, is presented in Fig. 5b. The Gaussian distributions of $K_{D}$ and $K_{F}$ generated from the Monte Carlo simulation are respectively illustrated in Fig. $5 \mathrm{~b}$ and Fig.5F, and the corresponding uncertainties in variables $\frac{\Delta p}{L}, \mu v_{i n}$, and $\rho_{i n} v_{i n}^{2}$ are shown in Fig. 52. In Fig. 5a, it can be observed that the experimental data follow the Darcy-Forchheimer equation, which is within the uncertainties. Furthermore, it can be seen that the flow enters the Forchheimer regime at higher velocities and deviates from the projected Darcy equation significantly as the superficial input velocity rises. At the last data point, this discrepancy reaches up to approx. $12 \%$, demonstrating the importance of using the Darcy-Forchheimer equation instead of the Darcy equation for these types of materials.

\begin{tabular}{ccccccc}
\hline sample ID & $K_{D}\left[10^{-14} m^{2}\right]$ & $\delta K_{D}\left[10^{-14} m^{2}\right]$ & $\frac{\delta K_{D}}{K_{D}}[\%]$ & $K_{F}\left[10^{-7} \mathrm{~m}\right]$ & $\delta K_{F}\left[10^{-7} \mathrm{~m}\right]$ & $\frac{\delta K_{F}}{K_{F}}[\%]$ \\
\hline UHTC-1 & 0.249 & \pm 0.024 & 9.64 & 0.0172 & $*$ & $*$ \\
UHTC-2 & 2.998 & \pm 0.055 & 1.84 & 1.587 & \pm 0.433 & 27.28 \\
UHTC-3 (prs) & 3.107 & \pm 0.061 & 1.96 & 1.312 & \pm 0.306 & 23.32 \\
UHTC-3 (pos) & 3.297 & \pm 0.063 & 1.91 & 1.262 & \pm 0.248 & 19.65 \\
UHTC-4 (prs) & 0.596 & \pm 0.047 & 7.89 & 0.0229 & & $*$ \\
UHTC-4 (pos) & 0.912 & \pm 0.048 & 5.26 & 0.0748 & & $*$ \\
UHTC-5 & 2.956 & \pm 0.064 & 2.17 & 1.105 & \pm 0.292 & 26.43 \\
UHTC-6 (prs) & 3.754 & \pm 0.069 & 1.84 & 1.704 & \pm 0.360 & 21.13 \\
UHTC-6 (pos) & 3.731 & \pm 0.073 & 1.96 & 1.538 & \pm 0.333 & 21.65 \\
UHTC-7 & 3.726 & \pm 0.061 & 1.64 & 1.968 & \pm 0.373 & 18.95 \\
UHTC-8 & 3.775 & \pm 0.067 & 1.78 & 1.741 & \pm 0.351 & 20.16 \\
\hline * The uncertainty in $K F$ could not be generated since the flow was in the lower bound of the mass flow meter's range where the uncertainty is relatively high.
\end{tabular}

Table 3 Permeability coefficients and their corresponding uncertainties. Note: 'prs' and 'pos' stand for pre-sand and post-sand, respectively. 
(a)

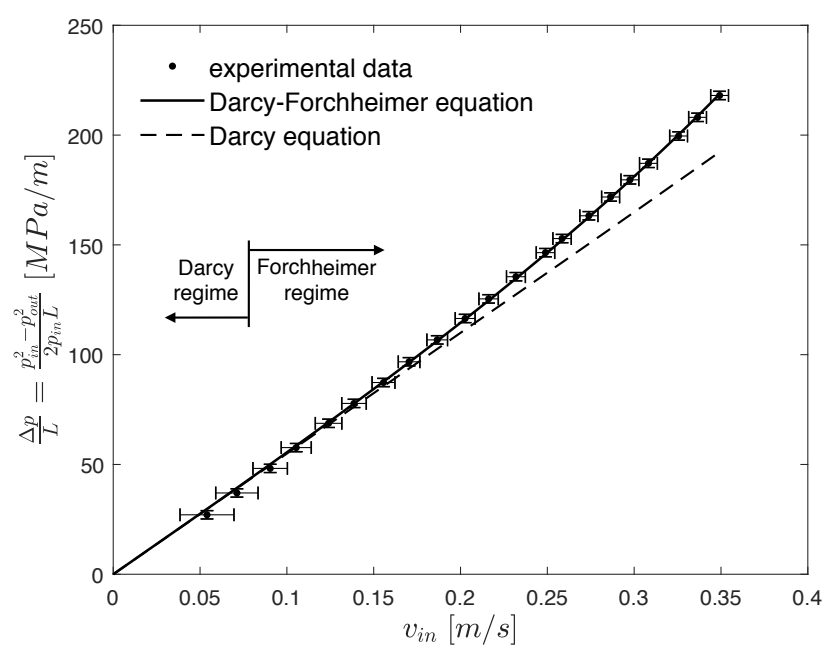

(c)

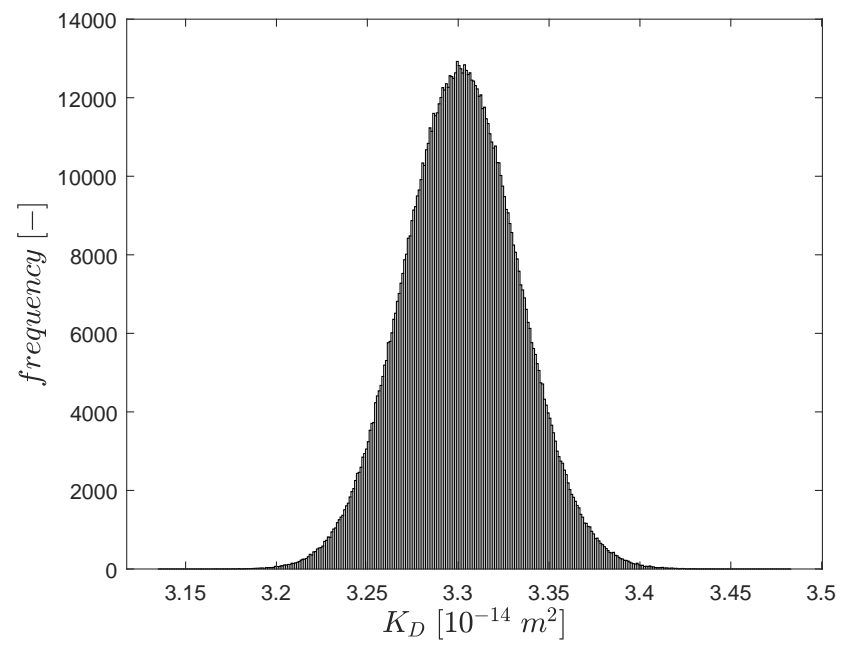

(b)

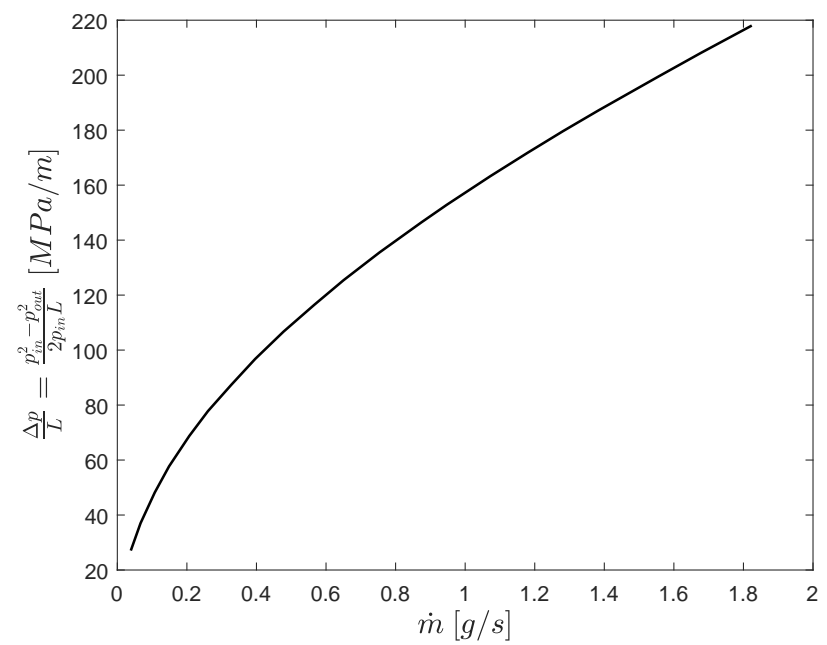

(d)

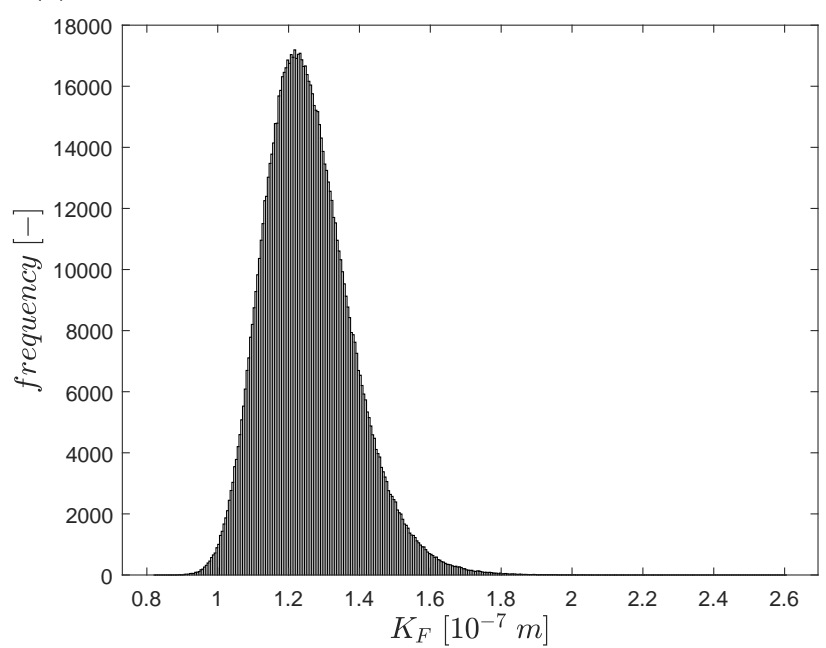

(e)

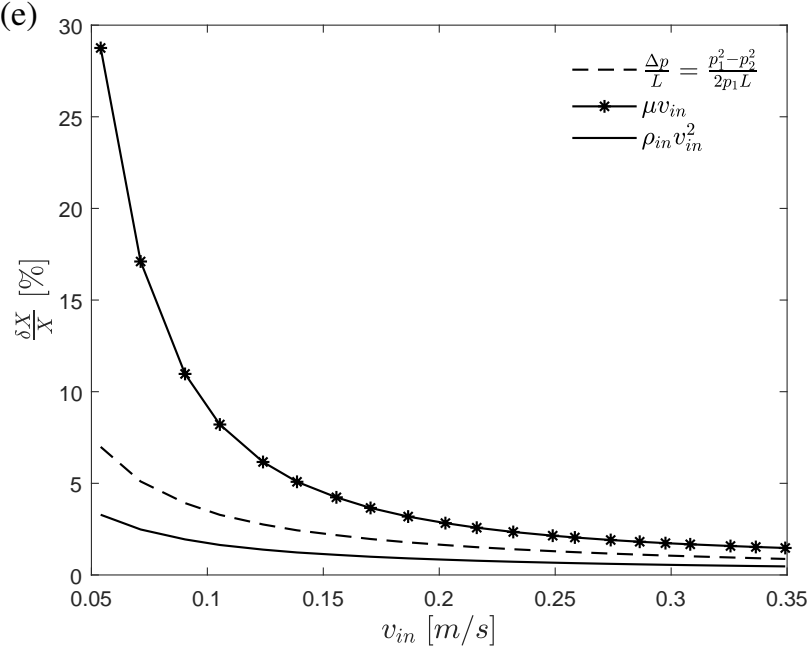

Fig. 5 Results for UHTC-3 (pos): normalised differential pressure versus (a) superficial input velocity and (b) mass flow rate through a through-flow area of $A=1.911 \times 10^{-4} \mathrm{~m}^{2}$; histogram of (c) $K_{D}$ and (d) $K_{F}$ for $1 \times 10^{6}$ events obtained from the Monte Carlo Simulation; (e) uncertainties of different variables for each data point with respect to their corresponding superficial input velocity. 
The effect of sanding on the overall permeability behaviour is presented in Fig. 6. Upon sanding, the samples demonstrated a clear improvement in their permeability, which is shown in Fig. 6a. The Darcy coefficient increased by $6.1 \%$ for UHTC-3 and 18.8\% for UHTC-4 (values obtained from Table 3), which are outside the uncertainty bounds of $1.96 \%$ and $7.89 \%$, respectively. For a given differential pressure, this translates into a rise in velocity by up to approx. $5 \%$ and $60 \%$ respectively for UHTC-3 and UHTC-4. Although the overall permeability is increased by sanding off the surface, there is a possibility that the residual grains from the process block the pores to some extent. This effect however was not possible to account for with the current experimental setup and processes; instead, the next batch of samples, i.e. UHTC-5 to UHTC-8, was treated in an ultrasonic bath. The effectiveness of the ultrasonic bath is demonstrated in Fig.60, where the permeability test was performed before and after sanding. Overall, the data sets taken before and after sanding fall atop each other. The change in the Darcy coefficient here is $0.6 \%$, which is within its uncertainty of $1.84 \%$ (see Table 3). This proves the ultrasonic bath to be effective, and consequently the sanding process can henceforth be circumvented.

(a)

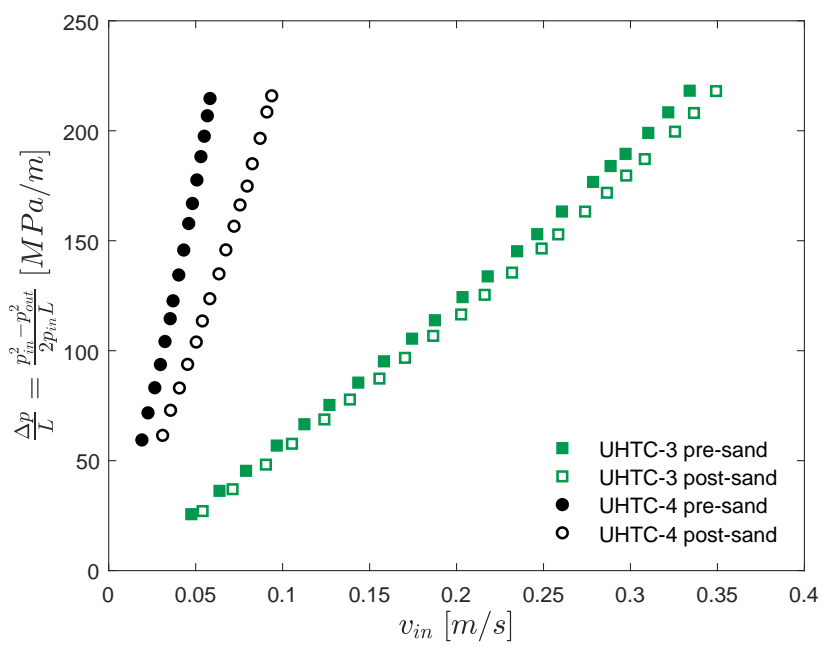

(b)

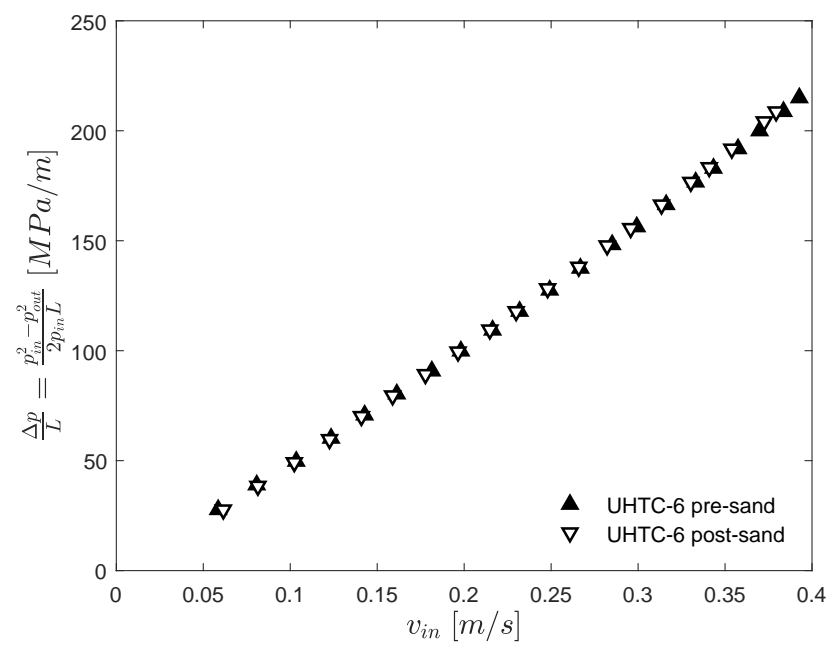

Fig. 6 Sanding effect on the permeability characteristics of (a) samples (UHTC-3 and UHTC-4) not treated in an ultrasonic bath and (b) a sample (UHTC-6) treated in an ultrasonic bath.

A comparison amongst all the eight UHTC samples in terms of their permeability characteristics is illustrated in Fig.7 .7 Here, it can be observed that, for a given differential pressure, the permitted flow through the starch sample, i.e. UHTC-1, is an order of magnitude lower than the partially sintered counterparts (except UHTC-4) since the permeability coefficients are an order of magnitude lower in comparison (see Table 3). This is due to the lower porosity of UHTC-1 compared to the rest (see Table 11), and could be due to the different porous structure in addition. 
(a)

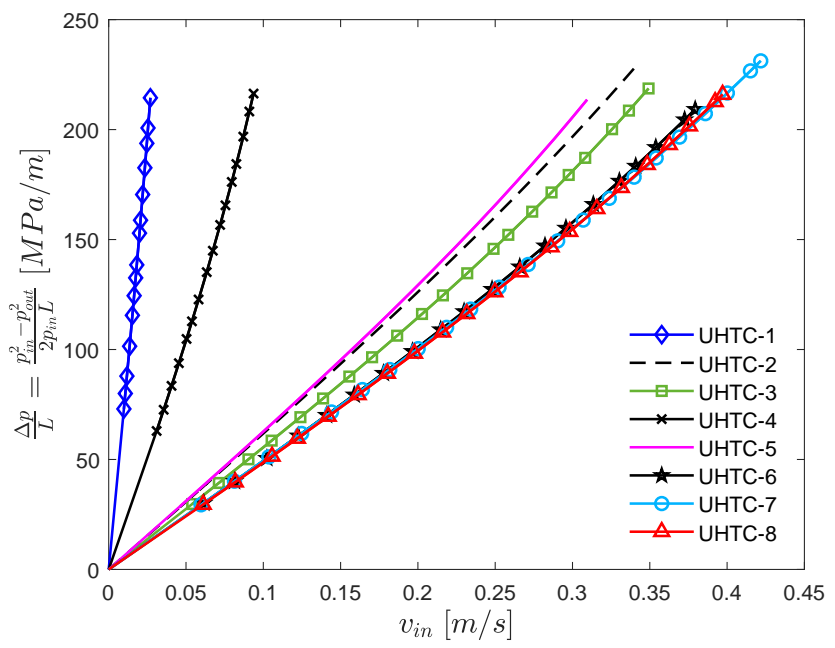

(b)

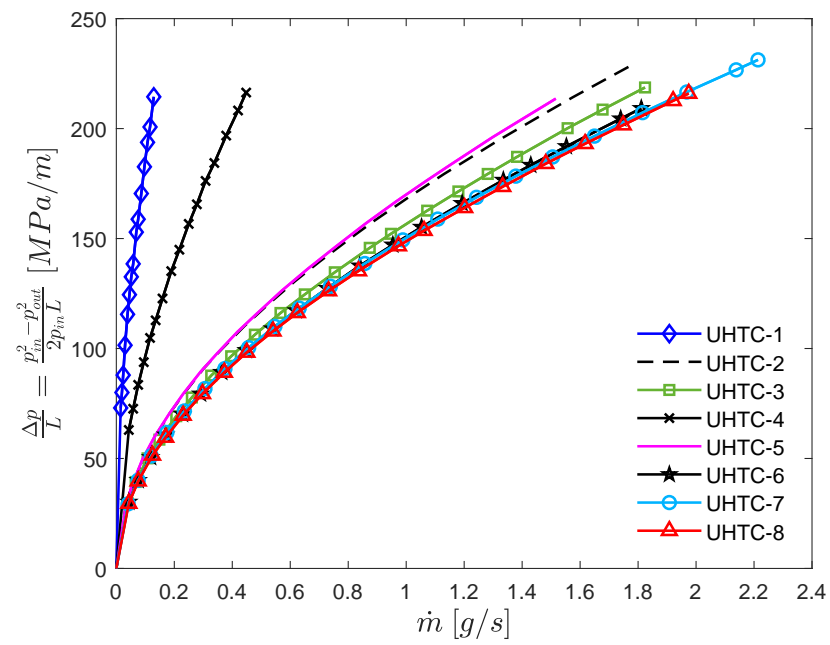

Fig. 7 Comparison amongst all samples: normalised differential pressure versus (a) superficial input velocity and (b) mass flow rate through a through-flow area of $A=1.911 \times 10^{-4} \mathrm{~m}^{2}$. Note: only post-sand data are presented, where applicable.

Furthermore, it can be seen that within the first batch of partially sintered samples, i.e. UHTC-2 to UHTC-4, that were not treated in an ultrasonic bath but were sanded, UHTC-4 is an outlier and the rest are fairly similar in terms of their superficial velocity (see Fig. 7p), through-flow mass flow rate (see Fig. 7p), and permeability coefficients (see Table 3). Analogous to the first batch, there is an outlier, i.e. UHTC-5, in the second batch, where the rest of the samples demonstrate a similar behaviour in terms of permeability. The deviation, however, is less compared to the first batch, and the data obtained from samples UHTC-6, UHTC-7, and UHTC-8 overlap fairly well. Moreover, the slight deviation in their permeability coefficients falls within the respective uncertainties-indicating the effectiveness of the ultrasonic bath and the uniformity amongst these UHTCs. In contrast, the outliers, UHTC-4 and UHTC-5, suggest that there are occasional non-uniformities within these samples, and emphasise the need for running the permeability test for each individual sample even if they are manufactured with the same conditions. These non-uniformities could occur from locally closed pores, i.e. increased amount of closed porosity, or local patches of more densified material. In addition, it is worth noting that the through-flow took place covering an area of $A=1.911 \times 10^{-4} \mathrm{~m}^{2}$, which is approx. $4-22 \%$ of the total surface area of the entire sample, depending on the sample's diameter. This means that not all local non-uniformities are captured within this permeability test. 


\section{Outflow Experiments}

In order to examine the outflow characteristics of the UHTCs, a bench-top rig has been designed, where the outflow velocity can be mapped and visualised using hot-wire anemometry and focused Schlieren imaging, respectively.

\section{A. Setup}

A machined UHTC sample (see Fig. 2r) is glued and sealed onto a cover-plate by silicon, and subsequently the cover-plate is attached to a plenum that is fitted with a pressure transducer (Gems 3100 Series) and a gas inlet as shown in Fig. 88. A K-type thermocouple is fed through the gas inlet. The plenum is located atop a set of motorised traverses (Thorlabs MTS50/M-Z8) that move in orthogonal directions with respect to each other. This allows for the the plenum, hence the sample, to be traversed in a two-dimensional plane, $x-y$. This setup is confined within an enclosure as a safety precaution—should the sample fail in operation.

Due to the fine porous structures of the UHTCs, a miniature hot-wire probe is employed (Dantec Dynamics P14). The hot-wire anemometry is run in CTA (Constant Temperature Anemometry) mode [25, 26]. During operation, the hot-wire probe is attached to a stationary support and the plenum is traversed at a pre-defined step-size on either direction (see Fig. $8 \mathrm{p}$ ). The height of the probe from the sample's surface, $z$, is adjusted by a fine translation stage (Thorlabs DTS50/M). Since the velocities of the outflow are relatively low, the probe is calibrated using the laminar pipe-flow method proposed by Lee \& Budwig [27]. The calibration data are fitted with King's law [25, 26]. Furthermore, measurements taken below the height of $z=3 \mathrm{~mm}$ are corrected according to Bhatia et al. [28] to account for the wall-effect on wall-near hot-wire anemometers.

(a)

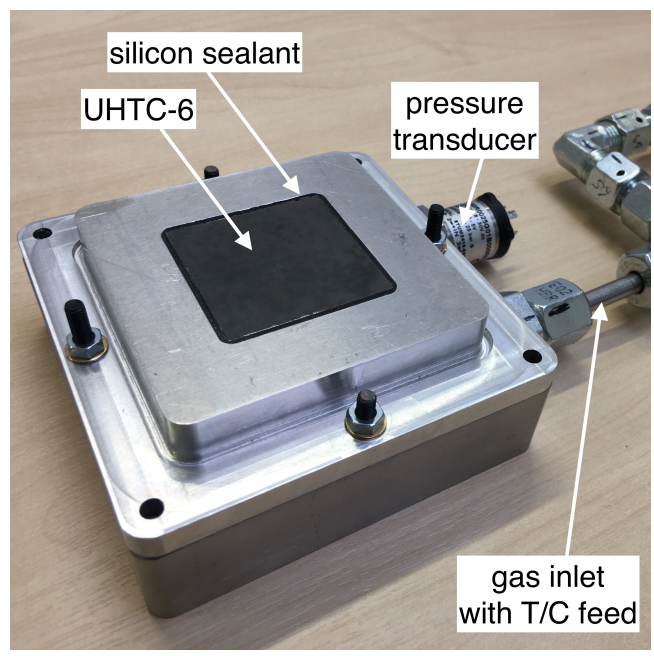

(b)

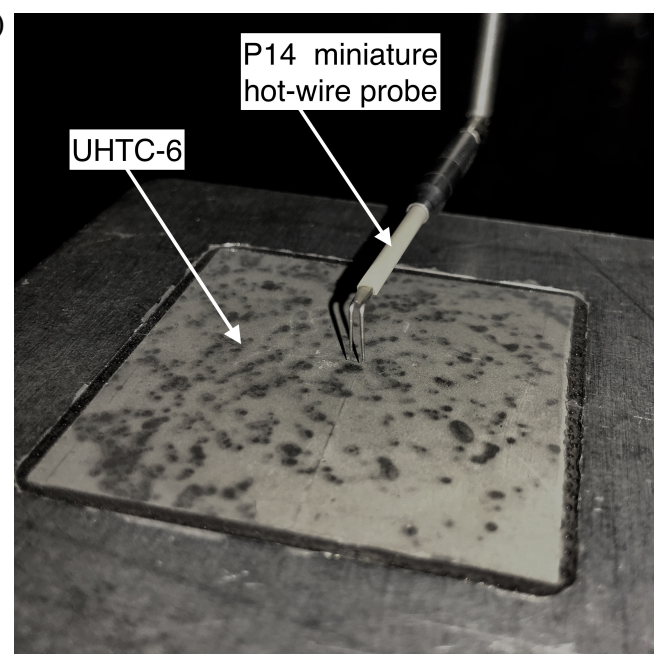

Fig. 8 (a) UHTC-6 attached to the plenum and (b) a miniature hot-wire probe, P14, in operation.

For each run, an area of $43 \mathrm{~mm} \times 43 \mathrm{~mm}$ is covered with a step-size of $1 \mathrm{~mm} \times 1 \mathrm{~mm}$. The plenum pressure, $p_{\text {plenum }}$, plenum temperature, $T_{\text {plenum }}$, and hot-wire data are acquired for each step. The overall process takes about 
3.5 hours to complete and the plenum pressure fluctuates slightly over time, which leads to minor discrepancies in the velocity across the sample. Hence, the obtained velocity from the hot-wire, $v_{h w}$, at each cell is normalised as

$$
\bar{v}_{\text {out }}=\frac{v_{\text {hw }} A_{z}}{v_{\text {out }} A_{0}},
$$

where $A_{z}$ and $A_{0}$ are respectively the through-flow areas at height $z$ and 0 (at the wall); $v_{\text {out }}$ is the superficial output velocity obtained from the Darcy-Forchheimer equation

$$
\frac{p_{\text {in }}^{2}-p_{\text {out }}^{2}}{2 p_{\text {out }} L}=\frac{\mu\left(T_{\text {out }}\right)}{K_{D}} v_{\text {out }}+\frac{\rho_{\text {out }}\left(p_{\text {out }}, T_{\text {out }}\right)}{K_{F}} v_{\text {out }}^{2},
$$

expressed in terms of output quantities. Here, the input and output conditions correspond to the atmospheric and plenum conditions, respectively, for each measurement location. The non-dimensional output velocity, $\bar{v}_{\text {out }}$, therefore incorporates the fluctuations in the plenum pressure and also shows how close the obtained velocity is compared to the theoretical Darcy-Forchheimer velocity, e.g. they would be equal at unity, i.e. $\bar{v}_{\text {out }}=1$. This also serves as a baseline quantity to compare the uniformity of a particular measurement location with its neighbouring ones. Note that $A_{0}$ is approximated from the hot-wire map evaluated at $z=1$ since the silicon glue seeps into the porous sample and thereby reduces the initial through-flow area of $39.5 \mathrm{~mm} \times 39.5 \mathrm{~mm}$.

The focused Schlieren setup is built around the aforementioned enclosure-containing the plenum on the traversing system—in a linear type setting (see Fig. 9a). Either side of the enclosure's wall is made of toughened glass to ensure optical access. The modern focusing Schlieren layouts from Weinstein [29] and Kouchi et al. [30] were followed to setup the current focused Schlieren system, which is comprised of (from left to right in Fig. 9a) an LED light source (Luminus PT-120-G-L11; collimated and focused), a Fresnel lens, a source grid, a commercial camera lens (Schlieren lens; focal length, $f=85 \mathrm{~mm}$ and $f$-number $=1.4$ ), a cut-off grid, another Fresnel lens, and a DLSR camera (Nikon D600, fitted with a lens of focal length, $f=50 \mathrm{~mm}$ and $f$-number $=1.4$ ). For the outflow experiments, the grids are installed in the vertical cut-off direction. Carbon dioxide is used as the injected gas to create the required density gradients in the surrounding air in the test section.

A demonstration of the depth of field of the current focused Schlieren setup is illustrated in Fig. 9p. Here, a jet of pressurised gas out of a tube of $2 \mathrm{~mm}$ outer diameter is presented at different planes with reference to the focal plane, denoted with ' $0 \mathrm{~mm}$.' The tube goes out of focus as it is moved from the focus plane towards (positive direction) and away (negative direction) from the Schlieren lens. During the outflow visualisation, the plenum is traversed as such that the desired plane on the sample coincides with the focal plane of the Schleiren system. Note that on the focal plane, the effective viewing window is approx. $25 \mathrm{~mm}$ wide with a resolution of approx. 40 microns per pixel. 


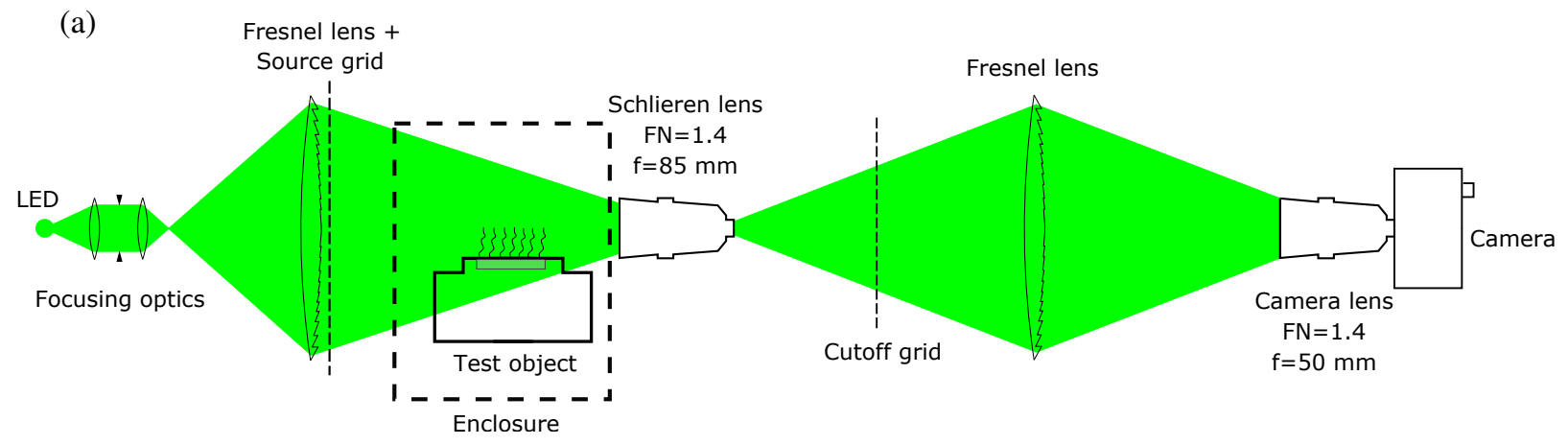

(b)
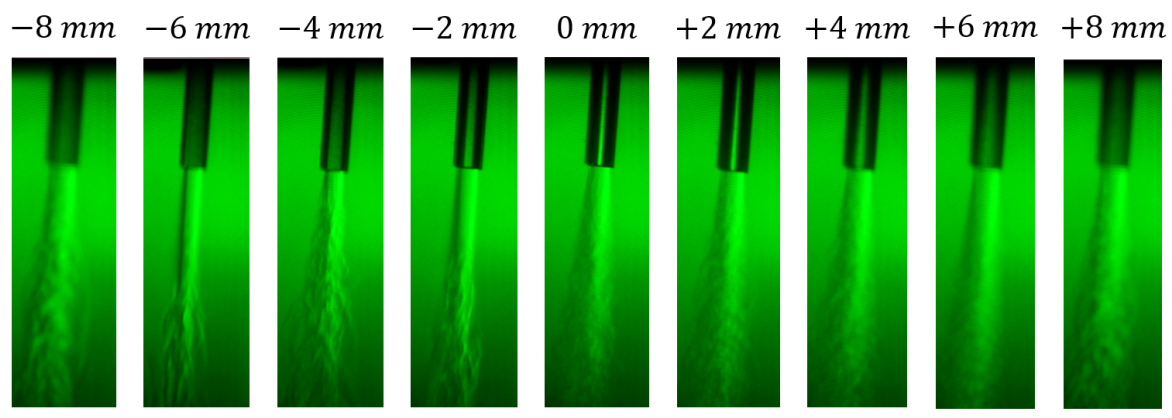

Fig. 9 (a) Schematic of the focused Schlieren setup for the outflow visualisation and (b) measurement of its depth of field.

\section{B. Results}

The velocity maps obtained from the hot-wire test conducted for UHTC-6 are presented in Fig. 10, where Fig. 10a, shows the placement of the reference frame for traversing with respect to the hot-wire probe. In Fig. 10p and Fig. 10k, the cases with plenum pressures $p_{\text {plenum }}=2 \operatorname{bar}(g)$ and $p_{\text {plenum }}=4 \operatorname{bar}(g)$ are respectively illustrated; the height of the probe for both is $z=1 \mathrm{~mm}$, and the mean output velocities according to Eq.11] are respectively $0.154 \mathrm{~m} / \mathrm{s}$ and $0.462 \mathrm{~m} / \mathrm{s}$. Further, an independent measurement of the mass flow rate through this sample yielded output velocities of $0.155 \mathrm{~m} / \mathrm{s}$ and $0.441 \mathrm{~m} / \mathrm{s}$, respectively, at these pressures. It can be observed that there exists an overall non-uniformity across the sample for both cases. The patterns of the non-uniformity are similar for both cases with the latter one showing them more pronouncedly. Interestingly, an extremely low permeability can be seen along a vertical line close to the centre. If compared closely to Fig. 10a, this vertical line can be observed physically. Moreover, several other imperfections can be noticed across the sample as well (see Fig. 10 and Fig. 8p)—suggesting that there exist local regions with low to almost no permeability from the manufacturing process per se. 
(a)
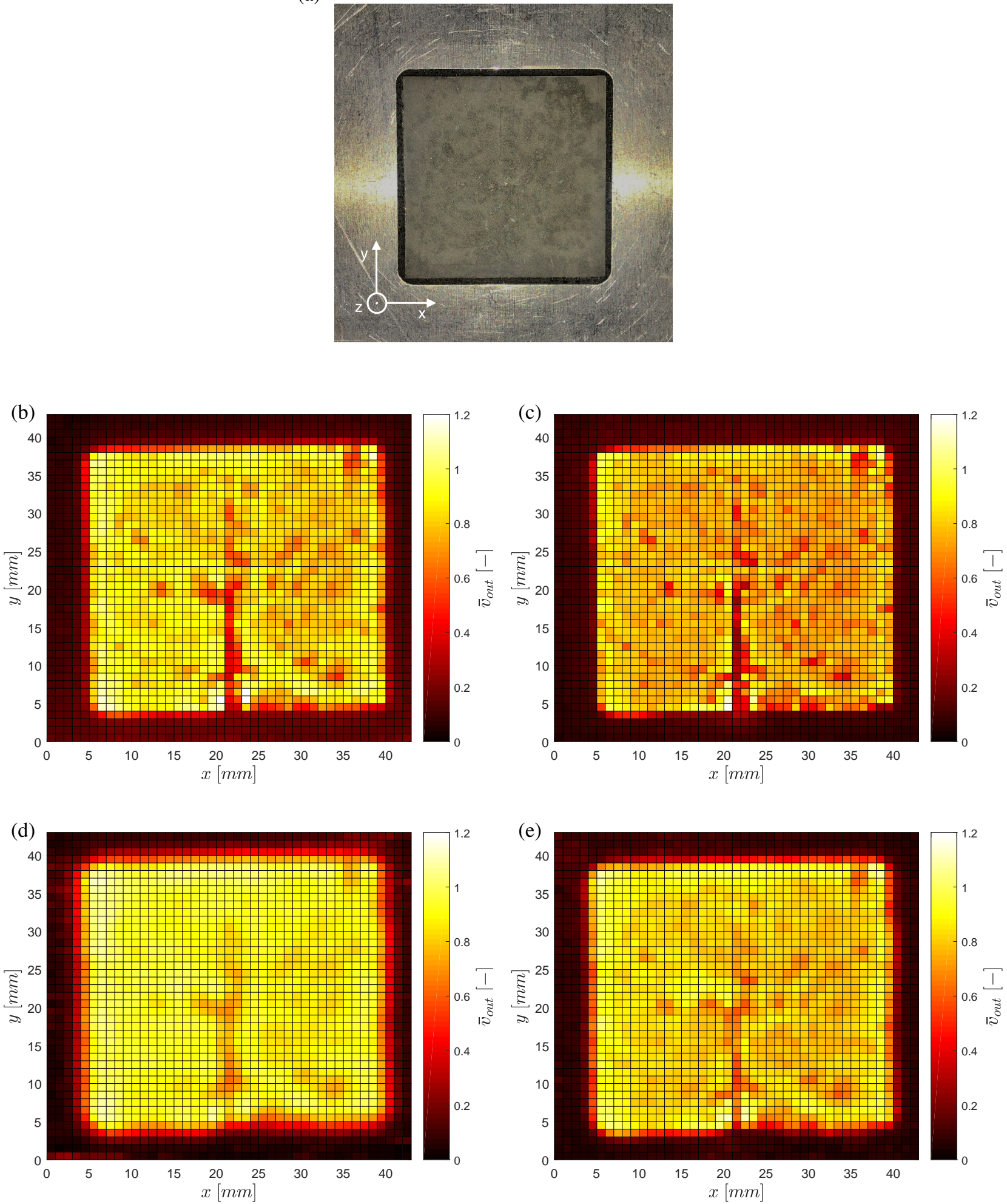

Fig. 10 (a) Reference frame for traversing; hot-wire anemometry maps in terms of the non-dimensional output velocity, $\bar{v}_{\text {out }}$, for UHTC-6: (b) $p_{\text {plenum }}=2 \operatorname{bar}(\mathrm{g}), z=1 \mathrm{~mm},(\mathrm{c}) p_{\text {plenum }}=4 \mathrm{bar}(\mathrm{g}), z=1 \mathrm{~mm}$, (d) $p_{\text {plenum }}=2 \operatorname{bar}(\mathrm{g}), z=5 \mathrm{~mm}$, and (e) pplenum $=4 \operatorname{bar}(\mathrm{g}), z=5 \mathrm{~mm}$. The injected gas is air. 
(a)

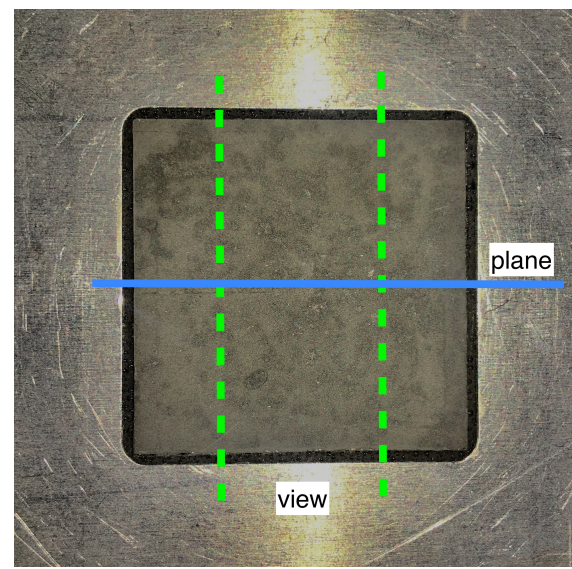

(b)

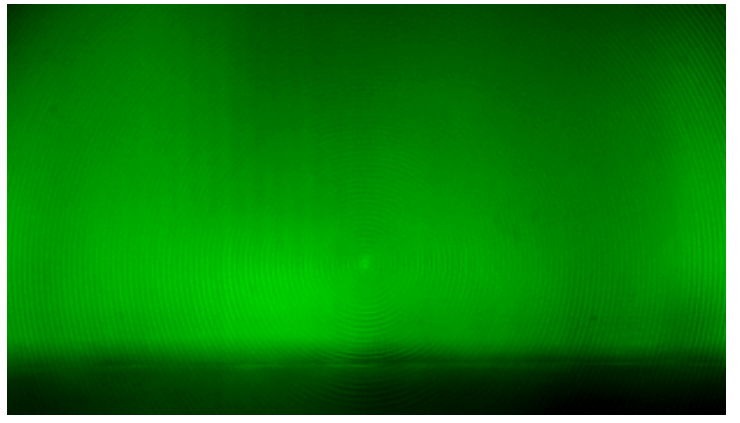

(d)

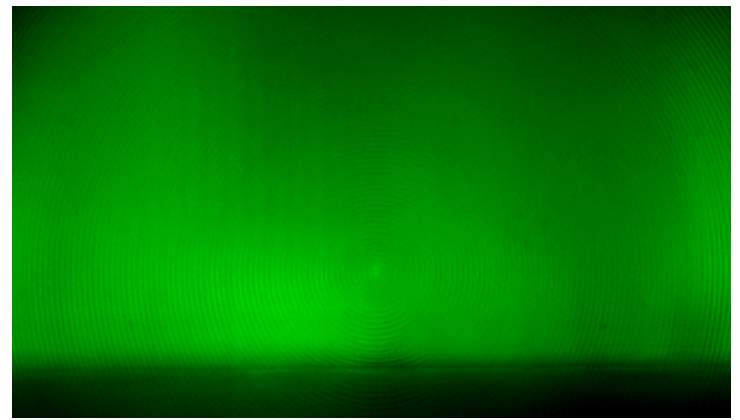

(f)

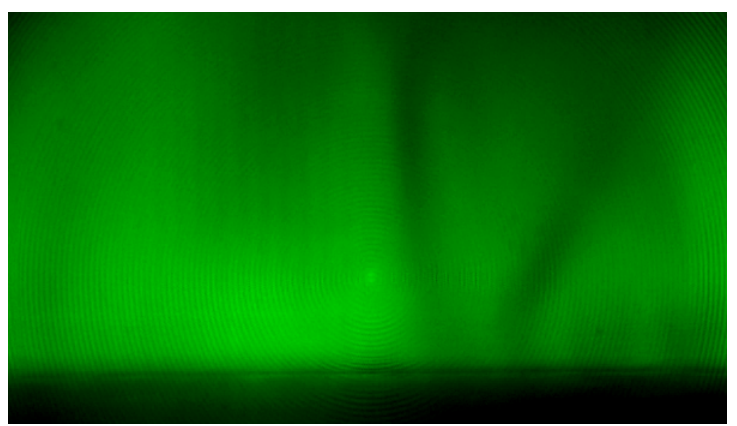

(c)

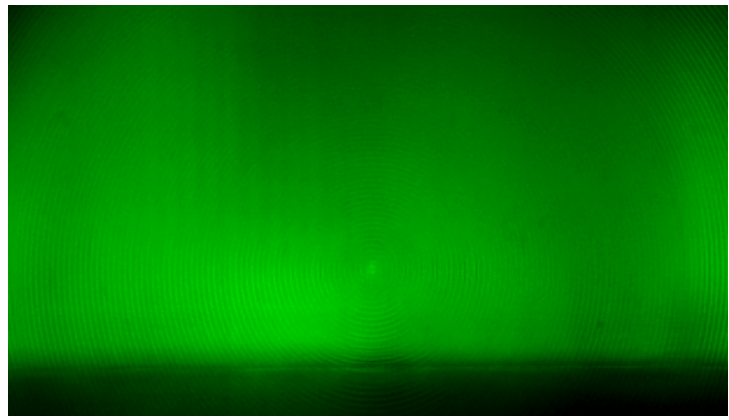

(e)

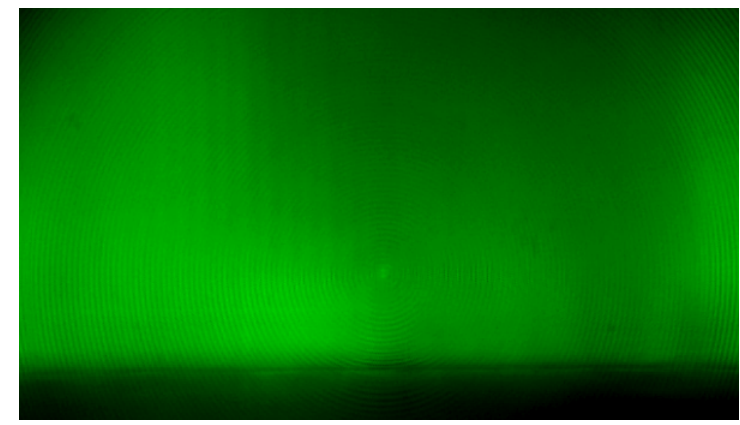

(g)

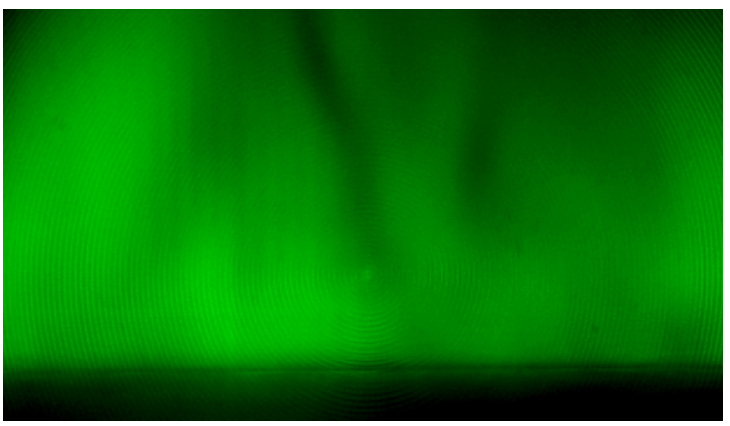

Fig. 11 Schlieren visualisation for UHTC-6 with varying plenum pressures: (a) selected viewing window (green) and focal plane (blue), (b) $p_{\text {plenum }}=0 \mathrm{bar}(\mathrm{g}),(\mathrm{c}) \mathrm{p}_{\text {plenum }}=2 \mathrm{bar}(\mathrm{g})$, (d) $p_{\text {plenum }}=2.5 \mathrm{bar}(\mathrm{g})$, (e) $p_{\text {plenum }}=3 \operatorname{bar}(\mathrm{g})$, (f) $p_{\text {plenum }}=3.5 \mathrm{bar}(\mathrm{g})$, and $(\mathrm{g}) p_{\text {plenum }}=4 \mathrm{bar}(\mathrm{g})$. Note: the width and height represented in figures (b) to (g) are approx. $25 \mathrm{~mm}$ and $14 \mathrm{~mm}$, respectively. The injected gas is carbon dioxide. 
(a)

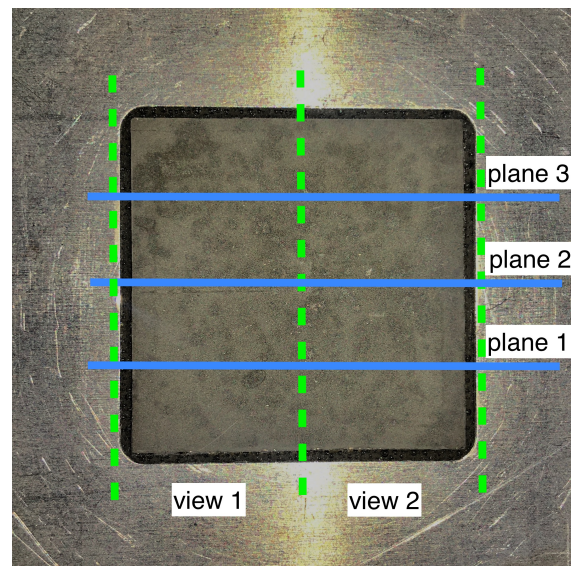

(b)

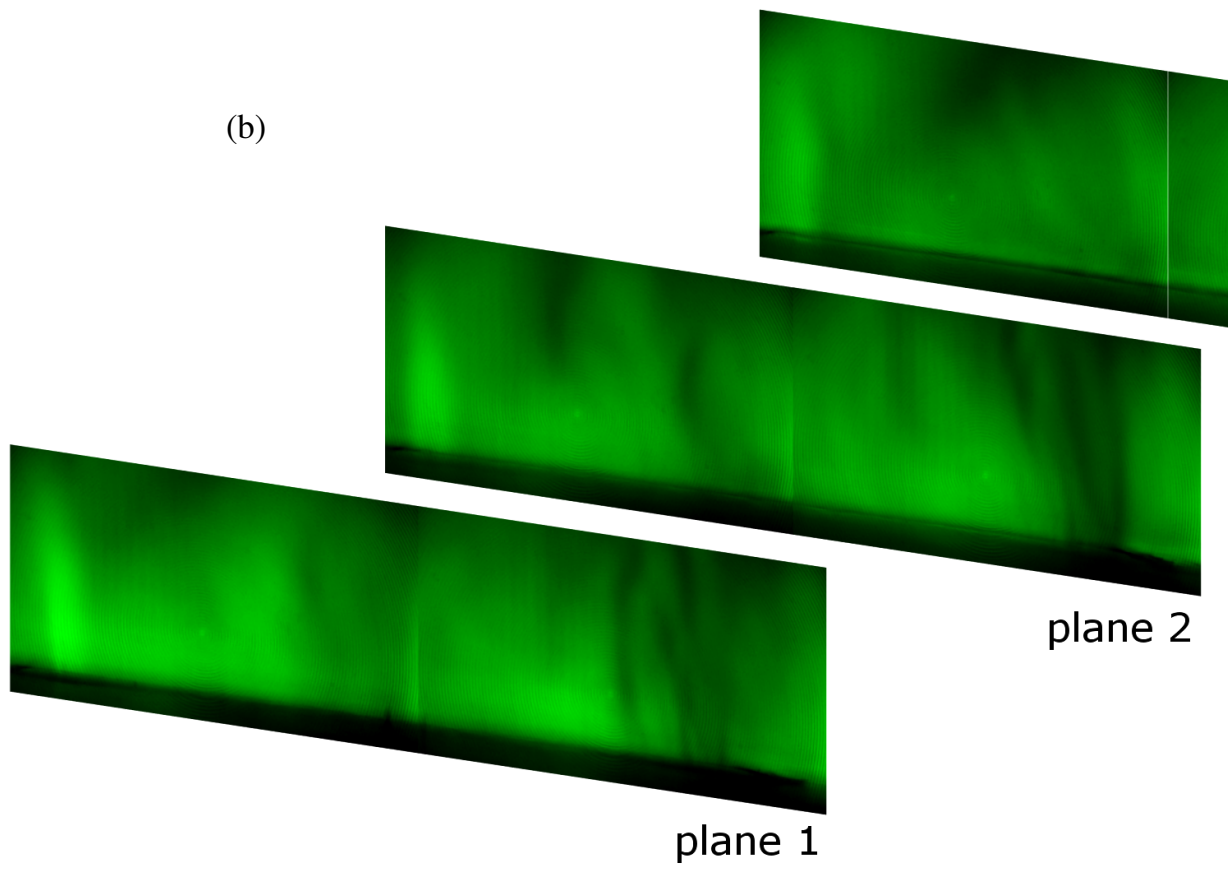

plane 3

plane 1

Fig. 12 Schlieren visualisation for UHTC-6 with varying focus planes at $p_{\text {plenum }}=4 \mathrm{bar}(\mathrm{g})$ : (a) selected viewing windows (green) and focal planes (blue) and (b) stitched photos obtained from the two viewing windows for plane 1, plane 2, and plane 3. Note: the width and height represented in figure (b) are approx. $50 \mathrm{~mm}$ and $14 \mathrm{~mm}$, respectively, for each plane. The injected gas is carbon dioxide.

Analogous to Fig. 10p and Fig. 10, the cases for a probe height of $z=5 \mathrm{~mm}$ are presented in Fig. 10d and Fig. 10d, respectively. In both cases, the velocity gradients are relatively smeared out as the mixing occurs; however, even at this height, the latter of the two still displays a fairly pronounced non-uniformity.

The results from the focused Schlieren visualisation for UHTC-6 are given in Fig. 11 and Fig. 12. In Fig. 11. the effect of varying plenum pressure on the outflow is illustrated. Fig. 11 a shows the placement of the viewing window and the selected focal plane, which in this case is at the middle of the sample. The reader is advised to take Fig. $11 \mathrm{p}$ as a reference where no flow exits. No apparent effect can be seen until the plenum pressure is as high as 
$p_{\text {plenum }}=3.5 \operatorname{bar}(g)$, where vertical structures appear. The corresponding videos reveal that these structures starts forming at about a plenum pressure of $p_{\text {plenum }}=3 \operatorname{bar}(g)$ and become prominent and unsteady as the pressure is increased, promoting the carbon dioxide to mix with the surrounding air.

In Fig. 12 a spatial comparison is shown at three different focal planes at a plenum pressure of $p_{\text {plenum }}=4 \operatorname{bar}(\mathrm{g})$. Note that the photos obtained from tests on either half of the sample (see Fig. 12p) are stitched to create a single view of the entire sample width (see Fig. $12 \mathrm{p}$ ). Here, relatively pronounced structures can be noticed on the edges at all three planes. This is due to the interaction between the injected pure carbon dioxide and the surrounding air, which is also the transitional region of the refractive indices and hence creates a strong signal.

\section{Conclusion}

Transpiration cooling is a potential technology that could enable a re-usable Thermal Protection System (TPS) for hypersonic vehicles, such as orbital re-entry vehicles. Whilst the traditional ablative TPS is high performing and robust, it requires replacement after each mission. To make an assessment of transpiration cooling applicability to real vehicles, further understanding of porous materials, manufacturing processes, and flow and heat transfer performance is required. In this paper, the permeability and external flow characteristics of porous Ultra-High-Temperature-Ceramics (UHTCs) made of zirconium diboride $\left(\mathrm{ZrB}_{2}\right)$ were investigated. A dedicated ISO standard permeability test rig was built and validated. Subsequently, eight UHTC samples—of which one was cast featured with starch fugitives and seven partially sintered - were tested for their permeability characteristics, and their respective Darcy and Forchheimer permeability coefficients were determined along with the corresponding uncertainties. It is shown that abrasion by sanding off the surface can increase the through-flow velocity for a given differential pressure across the sample. In additional, it is concluded that treating the samples in an ultrasonic bath eliminates the need of abrasion.

A bench-top test rig was built to study the outflow characteristics of these UHTC samples whilst transpiring, without a hypersonic cross-flow involved. Velocity maps of a transpiring sample were generated with the help of hot-wire anemometry at varying differential pressures, i.e. $2 \operatorname{bar}(g)$ and $4 \operatorname{bar}(g)$ across the sample. It is shown that a non-uniformity exists across the surface of the samples, which is pronounced at higher differential pressures. Furthermore, there are local regions where the permeability is very low. It is further demonstrated that the non-uniformity still exists even at a height of $5 \mathrm{~mm}$ for a differential pressure of $4 \operatorname{bar}(\mathrm{g})$. Finally, focused Schlieren using carbon dioxide as the injected gas revealed that unsteady structures occur as the differential pressure is increased—suggesting mixing between the injected gas and the surrounding air.

In future work, the outflow characteristics will be studied in presence of a hypersonic cross-flow in the High Density Tunnel at the Oxford Thermofluids Institute and the corresponding cooling performance of these transpiring UHTCs will be investigated. 


\section{Acknowledgements}

The funding for this research by the EPSRC grant 'Transpiration Cooling Systems for Jet Engine Turbines and Hypersonic Flight' (reference: EP/P000878/1) is duly acknowledged. The authors of this paper would like to thank the following people: Professor Luc Vandeperre, Dr Daniel Glymond, and Dr Laura Larribme of Imperial College London for their support regarding the ceramic samples; Professor Peter Ireland, Professor David Gillespie, Professor Luca Di Mare, and Jack Lavender for their contribution to the design and setup of the experimental rigs; Dr Luke Doherty for his support in performing the uncertainty analysis; Nikul Vadgama for his consultation on transpiration cooling; Gregory King, William Godfrey, Hal Surtell, Jason McCluskey, Duncan Blake, and David O'Dell of the maintenance and workshop teams for their assistance in building the experimental rigs; Gary Douglas and Grahame Faulkner for their support in assuring the health and safety measures for the experiments; and Christian Giebel for providing the SIKA-B 8 sample.

\section{References}

[1] Anderson, J. J. D., Hypersonic and High-Temperature Gas Dynamics, Second Edition, American Institute of Aeronautics and Astronautics, Reston ,VA, 2006.

[2] Varvill, R., and Bond, A., “The Skylon Space Plane: Progress to Realisation,” British Interplanetary Science, Vol. 61, 2008, pp. $412-418$.

[3] Esser, B., Barcena, J., Kuhn, M., Okan, A., Haynes, L., Gianella, S., Ortona, A., Liedtke, V., Francesconi, D., and Tanno, H., “Innovative Thermal Management Concepts and Material Solutions for Future Space Vehicles,” Journal of Spacecraft and Rockets, Vol. 53, No. 6, 2016, pp. 1051-1060.

[4] Tanno, H., Komuro, T., Itoh, K., Kuhn, M., Petkov, I., and Esser, B., “Transpiration cooling experiments in free-piston shock tunnel HIEST," 2016.

[5] Gülhan, A., and Braun, S., "An experimental study on the efficiency of transpiration cooling in laminar and turbulent hypersonic flows," Experiments in Fluids, Vol. 50, No. 3, 2010, pp. 509-525.

[6] Boehrk, H., "Transpiration Cooling at Hypersonic Flight - AKTiV on SHEFEX II," 11th AIAA/ASME Joint Thermophysics and Heat Transfer Conference, American Institute of Aeronautics and Astronautics, Reston, Virginia, 2014, p. 175.

[7] Dittert, C., Selzer, M., and Böhrk, H., "Flowfield and Pressure Decay Analysis of Porous Cones," AIAA Journal, Vol. 55, No. 3, 2017, pp. 874-882.

[8] Böhrk, H., and Beyermann, U., "Secure tightening of a CMC fastener for the heat shield of re-entry vehicles," Composite Structures, Vol. 92, No. 1, 2010, pp. 107-112.

[9] Langener, T., Wolfersdorf, J. V., and Steelant, J., "Experimental Investigations on Transpiration Cooling for Scramjet Applications Using Different Coolants,” AIAA Journal, Vol. 49, No. 7, 2011, pp. 1409-1419. 
[10] Schweikert, S., von Wolfersdorf, J., Selzer, M., and Hald, H., "Characterization of Actively Cooled Porous C/C Wall Segments According to Pressure Loss and Internal Temperature Distribution,” 2013.

[11] Löhle, S., Schweikert, S., and von Wolfersdorf, J., "Method for Heat Flux Determination of a Transpiration-Cooled Wall from Pressure Data," Journal of Thermophysics and Heat Transfer, Vol. 30, No. 3, 2016, pp. 567-572.

[12] BACOS, M. P., “Carbon-carbon composites : oxidation behavior and coatings protection,” Le Journal de Physique IV, Vol. 03, No. C7, 1993, pp. C7-1895-C7-1903.

[13] Gascoin, N., Fau, G., Gillard, P., Kuhn, M., Bouchez, M., and Steelant, J., "Comparison of Two Permeation Test Benches and of Two Determination Methods for Darcy's and Forchheimer's Permeabilities,” Journal of Porous Media, Vol. 15, No. 2012, 2012, pp. 705-720.

[14] Najmi, H., El-Tabach, E., Chetehouna, K., Gascoin, N., and Falempin, F., "Effect of flow configuration on Darcian and Forchheimer permeabilities determination in a porous composite tube," International Journal of Hydrogen Energy, Vol. 41, No. 1, 2016, pp. 316-323.

[15] Gascoin, N., "High temperature and pressure reactive flows through porous media," International Journal of Multiphase Flow, Vol. 37, No. 1, 2011, pp. 24-35.

[16] “BS EN ISO 4022:2006: Permeable sintered metal materials. Determination of fluid permeability,” , 2006.

[17] Wang, J., and Vandeperre, L. J., "Deformation and Hardness of UHTCs as a Function of Temperature," Ultra-High Temperature Ceramics: Materials for Extreme Environment Applications, edited by W. G. Fahrenholtz, E. J. Wuchina, W. E. Lee, and Y. Zhou, John Wiley \& Sons, Inc, Hoboken, NJ, 2014.

[18] Lee, W. E., Giorgi, E., Harrison, R., Maître, A., and Rapaud, O., "Nuclear Applications for Ultra-High Temperature Ceramics and MAX Phases," Ultra-High Temperature Ceramics, John Wiley \& Sons, Inc, Hoboken, NJ, 2014, pp. $391-415$.

[19] Sutherland, W., "LII. The viscosity of gases and molecular force," The London, Edinburgh, and Dublin Philosophical Magazine and Journal of Science, Vol. 36, No. 223, 1853, pp. 507-531.

[20] Nelder, J. A., and Mead, R., “A Simplex Method for Function Minimization,” The Computer Journal, Vol. 7, No. 4, 1965, pp. 308-313.

[21] Moffat, R. J., "Describing the uncertainties in experimental results," Experimental Thermal and Fluid Science, Vol. 1, No. 1, 1988, pp. 3-17.

[22] “Filter-Elements: High porosity sintered parts SIKA-B," GKN Sinter Metals Filters GmbH, 2003.

[23] Ergun, S., "Fluid flow through packed columns," Chemical Engineering Progress, Vol. 48, 1952, pp. 89-94.

[24] Coleman, H. W., and Steele Jr., W. G., Experimentation, Validation, and Uncertainty Analysis for Engineers, John Wiley \& Sons, Inc., Hoboken, NJ, USA, 2009. 
[25] Jørgensen, F. E., How to measure turbulence with hot-wire anemometers, Aug. 2005.

[26] Bruun, H. H., Hot-wire anemometry : principles and signal analysis, 2002.

[27] Lee, T., and Budwig, R., “Two improved methods for low-speed hot-wire calibration,” Measurement Science and Technology, Vol. 2, No. 7, 1999, pp. 643-646.

[28] Bhatia, J. C., Durst, F., and Jovanovic, J., "Corrections of hot-wire anemometer measurements near walls," Journal of Fluid Mechanics, Vol. 122, No. -1, 2006, pp. 411-431.

[29] Weinstein, L. M., "Review and update of lens and grid schlieren and motion camera schlieren," The European Physical Journal Special Topics, Vol. 182, No. 1, 2010, pp. 65-95.

[30] Kouchi, T., Goyne, C. P., Rockwell, R. D., and McDaniel, J. C., "Focusing-schlieren visualization in a dual-mode scramjet," Experiments in Fluids, Vol. 56, No. 12, 2015, p. 55. 